Industrial Health, 1977, 15, 159.

\title{
QUANTITATIVE CHEMICAL ANALYSIS OF CHRYSOTILE FIBRILS IN RAT LUNG TISSUE BY ANALYTICAL ELECTRON MICROSCOPY
}

\author{
A PRELIMINARY NOTE \\ Norihiko KOHYAMA ${ }^{\dagger}$, Kiyoyuki KAWAI ${ }^{\dagger}$, Saburo AITA ${ }^{\dagger}$, \\ Mikio SUZUKI ${ }^{\dagger \dagger}$ and Hisato HAYASHI ${ }^{\dagger \dagger}$ \\ $\uparrow$ National Institute of Industrial Health, 21-1, Nagao 6-chome, Tamaku, \\ Kawasaki 213 Japan \\ †tApplication Department, Electron Optics Division, JEOL Ltd., \\ Akishima, Tokyo 196 Japan \\ †t+Mining College, Akita University, Akita 010 Japan
}

(Received August 1, 1977)

A procedure of quantitative chemical analysis on a crysotile fiber under electron microscopy was developed, and was successfully adopted to a study on its changing chemical composition in situ during its long lasting residence in the rat lung.

Lungs were obtained from the rats, which were sacrificed at 4 and 28 months after an intratracheal insufflation of $10 \mathrm{mg}$ of the crysotile. Routine paraffin sections from those lungs were treated by means of carbon extraction technique and were submitted to analytical electron microscopy. Every single fiber identified under transmission EM was determined for the chemical composition by an simultaneous application of the $X$-ray microanalysis of energy dispersing type.

It was found that magnesium ion leached far faster than silica out of crysotile fibril during their residence in the lung tissue. It was also suggested that, in calculating the ratio of magnesium content to silica in the single fiber, rough estimation may also be possible on its past retention period in the lung tissue.

Preliminary determinations on the experimentally degradated crysotile in the test tube were also described. Results obtained from the $\mathrm{X}$-ray Fluorescence Spectrometry and the $X$-ray microanalysis of energy dispersive type were compared and discussed on possible application of the latter method to the crysotile fiber in vivo.

Recently, emphasis has been increasing on identifying and characterizing the individual microcomponents separately from a particulate material of very complexed constituents, which appeared in a variety of fields including atmospheric air pollution, forensic chemistry, corrosion, experimental petrology as well as studies in biological specimens from medical and biological fields.

The detection and analysis of the characteristic X-ray can be used to do a quantita- 


\section{N. KOHYAMA et al.}

tive and qualitative determination of chemical compositions. There are two different types of $\mathrm{X}$-ray spectrometry technique in conjunction with the electon beam excitation. One is the wavelength dispersive $\mathrm{X}$-ray spectrometry, using a crystal spectrometer. Although this spectrometer has the excellent energy resolving power, it has some disadvantage for the above mentioned purpose of separate analysis of individual particulate. Moreover, in this system flat specimen surface and considerably high beam currents to produce sufficient X-ray emission are required. The analytical crystals of this system must be varied on the Rawland circle geometry to make up one Bragg angle, and a spectrometer can detect the radiation of only one element at a time. Thus the whole procedure is rather tedious and time consuming.

The other technique is energy dispersive $\mathrm{X}$-ray analysis which permits simultaneous multielement analysis of all elements above atomic number 11 . The energy resolving power is rather poor, about one fiftieth as compared with the wavelength dispersive system, however, the considerably small area can be analyzed by this system. On the other hand, this system has several advantages as, 1) Complete qualitative data can be aquired about 30 times faster than the wavelength dispersive system, 2) The detection has a wide allowance for the location and the surface state of specimens, 3) The high efficiency of this system allows sufficient acquisition of data under far lower electron density and smaller probe size, which means the spatial resolving power is improved. Thus, this system has a good deal of practical convenience despite of some drawback in quantitation. In recent years, this analytical method has been usefully applied to a variety of biological and environmental materials. ${ }^{1-7)}$

Since the relation of asbesti form minerals to human disease has been well docummented, ${ }^{8)}{ }^{-10)}$ individual asbestos fibers and/or body cores in lung tissus have been the subject of observation by transmission electron microscope. Rubin and Maggiore ${ }^{11)}$ demonstrated that the combination of electron optical and X-ray analytical equipments was useful to obtain qualitative and quantitative informations on the fibrous dust in the tissue. Recently, "analytical electron microscope" (AEM) has been developed facilitating observations by the transmission electron microscope (TEM), energy dispersive X-ray microanalysis and selected area electron diffraction (SAED) on the same specimen with an instantaneous switching. However, the quantitative chemical analysis by AEM has not been developed sufficiently up to date.

Chrysotile was found as a very common constituent of the dust from the lung of a rural population group in western industrial countries. Heppleston ${ }^{12)}$ found, however, that only $12-30 \%$ of the asbestos fibers in lung tissue were optically visible, but the majority of these fibers were amphibole fibers. Langer et al. ${ }^{13)}$ detected many other kinds of fibers than chrysotile fibers in the lung of dwellers in New York city. Pooley ${ }^{14)}$ showed also that fibrous minerals other than chrysotile were present in asbestos lung tissue from the Canadian chrysotile mining industry.

To contribute to these problems, this paper describes a new approach to quantitative determination of individual chrysotile fibrils by analytical electron microscopy in con- 


\section{CHRYSOTILE FIBRILS IN LUNG}

junction with the result of X-ray fluorescence spectrometry. This method, furthermore, was applied for the observation of chrysotile fibrils in vivo, in order to obtain the information of the changing chemical composion for chrysotile fibrils during their long lasting residence in the rat lung.

\section{Materials ANd Methods}

\section{Instrumentation}

The AEM used in this study consists of a transmission electron microscope (JEM$100 \mathrm{C}$ ), side entry goniometer (SEG), scanning attachment (ASID), and energy dispersive $\mathrm{X}$-ray spectrometer (EDAX). The AEM was operated with accelrating voltage $100 \mathrm{kv}$. The TEM shows excellent image capability, and superior SAED capability, and can resolve ultraminute structures. The scanning transmission electron (STEM) image is able to resolve the lattice image of $15 \AA$ when the ASID attached to this TEM. The SAED pattern is easily obtained from a microarea on the subject using the SEG, and its chemical compositions of the same area smaller than 200A in size can also be analyzed by the ASID and the NDS. This procedure can be got through without any realigment of the electron microscope. These factors lead to overall ease of operation, accurate morphological identification, and time sparing analysis. The AEM can be easily used for the measurement of characteristic X-ray intensities from fibers of asbestos. While the electron probe is scanned over the specimen, or the selected area, or fixed on a spot position, the elements are detected and computed by the internal minicomputor. They are shown on display or teletype connected with the computor.

The insturument of X-ray fluorescence spectrometry used for this analysis was a type which was especially suitable for light-element such as $\mathrm{Si}$ and $\mathrm{Mg}$ elements (JSX$60 \mathrm{S5}$; JEOL, Co.). The instrumental conditions were:

$\begin{array}{ll}\text { Target } & \mathrm{Rh} \\ \text { A.C.C. voltage } & 30 \mathrm{KV} \\ \text { Current } & 30 \mathrm{~mA} \\ \text { Atmosphere } & \text { in vacuum (<0.1 Torr.) } \\ \text { Fix time } & 10 \mathrm{sec} \text { (Repeated three times) } \\ \text { Crystal } & \text { PET for Si } \mathrm{K}_{\alpha} \\ & \text { ADP for Mg K } \alpha \\ \text { Specimen holder } & \text { Titanium plate of } 25 \mathrm{~mm} \phi\end{array}$

\section{Specimen preperation}

Asbestos specimen used in this study was a chrysotile occured in Cassier Mine, Canada. Impurities were not observed by an optical microscope, $\mathrm{X}$-ray analysis and DTA. They were cut three times by Cutting Mill (Wiley Type.). The fibrils were despersed into dilute hydrochloric acid aqua $(0.12 \mathrm{~N})$ of about $40^{\circ} \mathrm{C}$ for several steps from $15 \mathrm{~min}$. to $24 \mathrm{hr}$ with occasional shaking. They were separated from the solution and 


\section{N. KOHYAMA et al.}

washed with distilled water for several times using centrifugation.

Chrysotile fibrils thus treated were analyzed by both AEM and X-ray fluorescence spectrometry to determine their chemical composition. A small amount of the treated chrysotile fibrils were dispersed into distiled water, and one droplet was put on a coppergrid for AEM analysis. On the other hand, about $200 \mathrm{mg}$ of those treated specimens were dispersed into small amount of purified water and filtrated on a memblane filter (diameter of about $40 \mathrm{~mm} \phi$ ). Succeedingly, they were pressed by oil-press machine for making the flat surface specimens for X-ray fluorescence spectography. It was expected that the chemical compositions would be gradually changed with increasing treatment periods.

\section{Preperation of standard calibration curves for AEM analysis}

In a specimen which is thin enough to be examined by AEM, the intensity of the characteristic X-ray can not be compared directly with the results from a bulk standard specimen, because the observed X-ray intensity is a function of the specimen thickness as well as of the chemical composition. It has been therefore, impossible to apply the EPMA (using wavelength dispersive $\mathrm{X}$-ray spectrometer) to the quantitation of thin foil specimen or small particulates in a lung tissue.

Recently Namae ${ }^{16)}$ (1975) proposed a new procedure of quantitative analysis for a thin foil specimen by AEM. The method is considered to be useful for an extremely thin or a very small particle specimen regardless of the thickness or the size of the specimen, as required in our present study. The principle and used abbreviations are given in Appendix. By this method, we can determine directly the absolute weight, grams, of the object elements in a specimen. The weight percent of each element, of course, can be easily calculated when the absolute weight of all the component elements are measured in the specimen. This quantitative method proposed by Namae was used in this study for the determination of $\mathrm{Si}$ and $\mathrm{Mg}$ contents in chrysotile fibrils.

To accomplish this quantitative chemical analysis, we must know the value of $\left(W_{s t} / I_{s t}\right)$ presented in the equation (3) in Appendix for each element previously. First, values about the relation of $\rho$ (current density of electron probe) and $\alpha\left(W_{s t} / I_{s t}=\mathrm{gram} / \mathrm{cps}\right.$ ) for $\mathrm{Si}$ and $\mathrm{Mg}$ elements were obtained (Fig. 1) for chrysotile analysis.

The standard specimens of $\mathrm{Si}$ and $\mathrm{Mg}$ in thin films, were prepared by their homogeneous evaporation in vacuum on rock salt crystal coated with carbon film. The thickness was $250-400 \AA$, when measured by optical interferometric microscope. The characteristic $\mathrm{X}$-ray intensity for $\mathrm{Si}$ and $\mathrm{Mg}$ from the thin films were measured by AEM under accelerating voltage of $100 \mathrm{KV}$ and various probe densities. Each characteristic $\mathrm{X}$-ray intensity on the peak and back ground was measured for $100 \mathrm{sec}$ on one analysis, and the average of 10 analysis were obtained. The $\alpha$ (gram/cps) is shown against the probe density (ampere/ $\mu \mathrm{m}^{2}$ ) in Fig. 1 . The $\alpha$ in Fig. 1 is a converted one by the value of $\rho$, which multiplied by the characteristic X-ray intensity from the object element $\left(I_{u n k}\right)$ products the weight of the object element $\left(W_{u n k}\right)$, gram. 


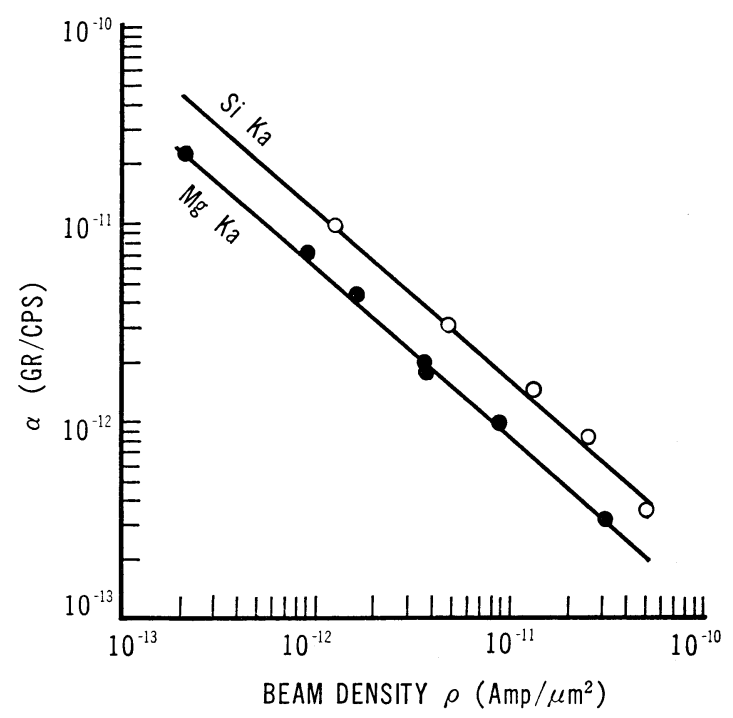

Fig. 1. The observed relation of (probe density) and $(W / I=\mathrm{gr} / \mathrm{cps})$

Preperation of standard calibration curves for $X$-ray fluorescence spectrography

Standard specimens for X-ray fluorescence spectrometry were prepared by mixing the powder of $\mathrm{SiO}_{2}, \mathrm{MgO}$, and starch with the respective weight percent as shown in Table 1. The starch was used as a substitution of the structural water of chrysotile. The mixing powders of the ternary components were dispersed into water and filtrated on a memblane filter, and pressed by oil-press machine with $25 \mathrm{~kg} / \mathrm{cm}^{2}$ pressue. Standard calibration curves for the standard specimens obtained by the instrumental condition mentioned above, were shown in Fig. 2 and 3, which were used for the quantitative chemical analysis by $\mathrm{X}$-ray fluorescence spectrometry.

Table 1. Standard samples for X-ray fluolescence spectrography.

\begin{tabular}{cccc}
\hline Sample No. & $\mathrm{SiO}_{2}(\%)$ & $\mathrm{MgO}(\%)$ & Starch $(\%)$ \\
\hline 1 & 50.0 & 36.0 & 14.0 \\
2 & 47.0 & 39.0 & 14.0 \\
3 & 44.0 & 42.0 & 14.0 \\
4 & 41.0 & 45.0 & 14.0 \\
\hline
\end{tabular}

Standard samples are the mixture of $\mathrm{SiO}_{2}, \mathrm{MgO}$ and starch powders.

\section{Results AND Discussion}

Observed value for the acid treated chrysotile fibril by $A E M$ analysis and $X$-ray fuorescence spectrometry

The $\mathrm{Si}$ and $\mathrm{Mg}$ composition of the chrysotile fibril treated with dilute hydrochloric acid was measured by AEM. Analysis for a single chrysotile fibril of every treated 
N. KOHYAMA et al.

time was performed with the same condition as the preparation of standard calibration curves. The absolute weights of $\mathrm{Si}$ and $\mathrm{Mg}$ for each fibril were obtained using the standard calculation curves of Fig. 1, and were averaged and expressed as a representative value for every treated time. Each element of $\mathrm{Si}$ and $\mathrm{Mg}$ was recalculated in assuming that the weight of $\mathrm{Si}$ plus that of $\mathrm{Mg}$ is constant $\left(W_{\mathrm{Si}}+W_{\mathrm{Mg}}=1\right)$ and shown as the oxide form in Fig. 4. The weight percent of $\mathrm{SiO}_{2}$ and $\mathrm{MgO}$ are shown vertical axis

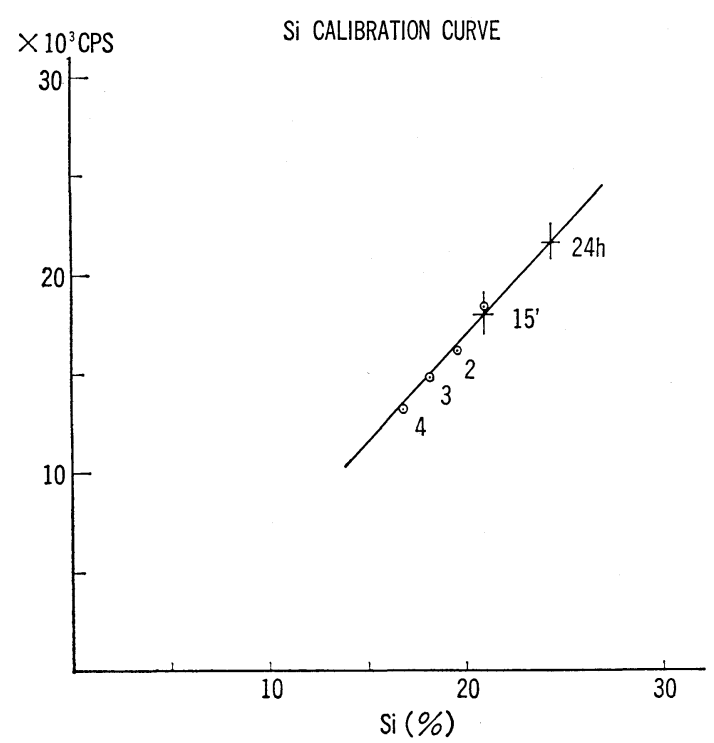

Fig. 2. Standard calibulation curve of $\mathrm{Si}$ for X-ray fluolescence spectrography.

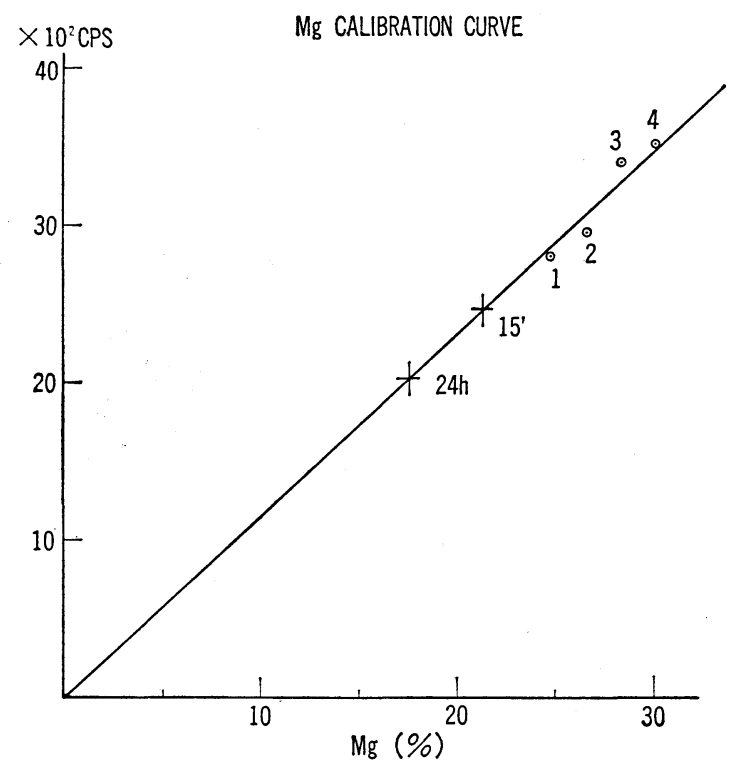

Fig. 3. Standard calibulation curve of $\mathrm{Mg}$ for $\mathrm{X}$-ray fluolescence spectrography. 


\section{CHRYSOTILE FIBRILS IN LUNG}

and the treated time horizontally. The relative mass of $\mathrm{Mg}$ ions in the fibril decreased gradually when the acid treatment was prolonged, and the $\mathrm{Si}$ ions showed apparent increase. Increase of $\mathrm{Si}$ content may be regarded as a reflection of dissolution of $\mathrm{Mg}$ ions, because the fibril volume is diminished by the dissolution. However, there remains still a possibility of $\mathrm{Si}$ being also dissolved from the fibril to some extent.

The measured values showed considerable variation with the fibrils and the average

Table 2. Chemical composition of chrysotile treated by hydrochloric acid.

\begin{tabular}{cccc}
\hline Time & $\mathrm{SiO}_{2}$ & $\mathrm{MgO}$ & Total \\
\hline $15^{\prime}$ & $44.8(55.8) \%$ & $35.5(44.2) \%$ & $80.3 \%$ \\
$30^{\prime}$ & $45.3(56.3) \%$ & $35.2(43.7) \%$ & $80.5 \%$ \\
$1 \mathrm{~h}$ & $46.1(57.0) \%$ & $34.8(43.0) \%$ & $80.9 \%$ \\
2 & $47.0(57.8) \%$ & $34.3(42.2) \%$ & $81.3 \%$ \\
3 & $47.4(58.4) \%$ & $33.7(41.6) \%$ & $81.1 \%$ \\
4 & $48.1(59.1) \%$ & $33.3(40.9) \%$ & $81.4 \%$ \\
5 & $48.3(59.4) \%$ & $33.0(40.6) \%$ & $81.3 \%$ \\
6 & $48.5(59.9) \%$ & $32.5(40.1) \%$ & $81.0 \%$ \\
8 & $48.7(60.9) \%$ & $31.9(39.1) \%$ & $81.6 \%$ \\
10 & $49.2(61.2) \%$ & $31.2(38.8) \%$ & $80.4 \%$ \\
16 & $50.4(62.8) \%$ & $29.9(37.2) \%$ & $80.3 \%$ \\
20 & $51.3(63.6) \%$ & $29.4(36.4) \%$ & $80.7 \%$ \\
24 & $51.9(64.2) \%$ & $29.0(35.8) \%$ & $80.9 \%$
\end{tabular}

Original sample: $\mathrm{SiO}_{2} 40.85(49.8) \%, \mathrm{MgO} 41.38(50.2) \%, \mathrm{Fe}_{2} \mathrm{O}_{3} 2.24 \%, \mathrm{H}_{2} \mathrm{O}$ 13.75\%, Total $98.22 \%$.

The value in parenthesis are those of recalculated as $\mathrm{SiO}_{2}+\mathrm{MgO}=100 \%$.

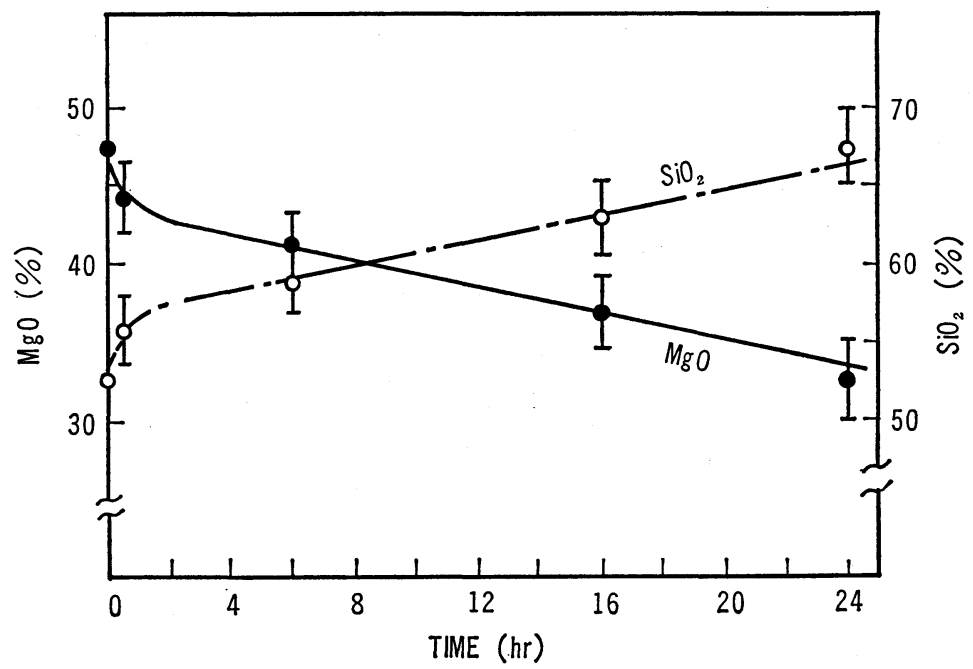

Fig. 4. The $\mathrm{SiO}_{2}$ and $\mathrm{MgO}$ contents in the treated chrysotile fibril measured by AEM. 


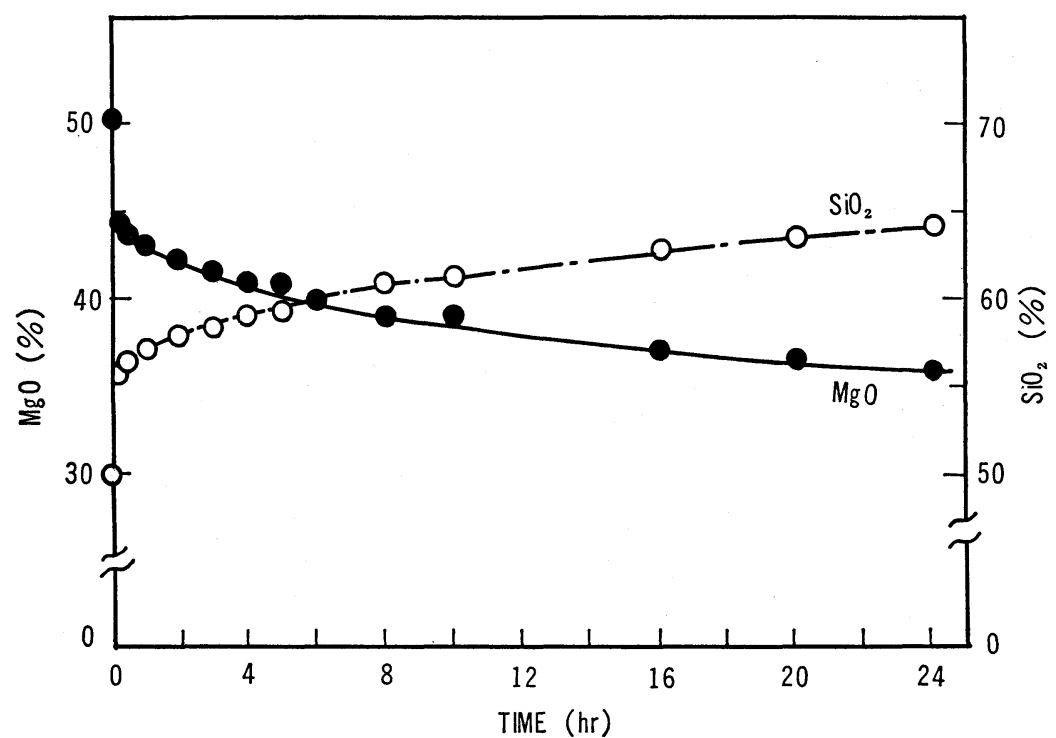

Fig. 5. The $\mathrm{SiO}_{2}$ and $\mathrm{MgO}$ contents in the treated chrysotilee specimens measured by X-ray fluolescence spectrography.

measurement error for each values were about $+3 \%$.

The same specimen of acid treated chrysotile fibrils were also measured by $\mathrm{X}$-ray fluorescence spectrography under the same instrumental condition used for the standard calibration in the Fig. 2 and 3. The results were listed in Table 2 as the oxide form. The total percent of the both oxide showed almost similar values of $80-81 \%$ for all the specimens. The remainder of $20-19 \%$ is considered to be $\mathrm{H}_{2} \mathrm{O}$ percent. These values were recalculated as $\mathrm{SiO}_{2}(\%)+\mathrm{MgO}(\%)=100(\%)$ and shown in Fig. 5. It was shown again that the $\mathrm{Mg}$ ions in the chrysotile fibrils dissolved rapidly into $\mathrm{HCl}$ solution, and that the $\mathrm{Si}$ ions showed apparent increase.

Comparing with the result of AEM analysis in Fig. 4 and that of $\mathrm{X}$-ray fluorescence spectrometry in Fig. 5, there is obvious tendency to increase in amount of $\mathrm{Si}$ and to decrease in amount of magnesium in acid treated chrysotile fibrils, in proportion as treated time was prolonged. Each point in Fig. 4 was averaged for a few separated chrysotile fibrils, while those of X-ray fluorescence spectrography were from a bulk of about $200 \mathrm{mg}$ of chrysotile fibrils. Most of points in Fig. 5 fall within statistical variation of the corresponding points in Fig. 4. Therefore, it can be said that the result of AEM agrees quite well with that of $\mathrm{X}$-ray fluorescence spectrography. Hence, it can be concluded that the quantitative chemical analysis of single chrysotile fibril by AEM would be possible within the variations of a few percent, and it was achieved on a few fibrils. The absolute weight of the objective element in a specimen may also be able to be determined directly by this method.

\section{Application for chrysotile fibrils in rat lung tissues}

The quantitative analysis by AEM mentioned above, was applied to evaluate a 


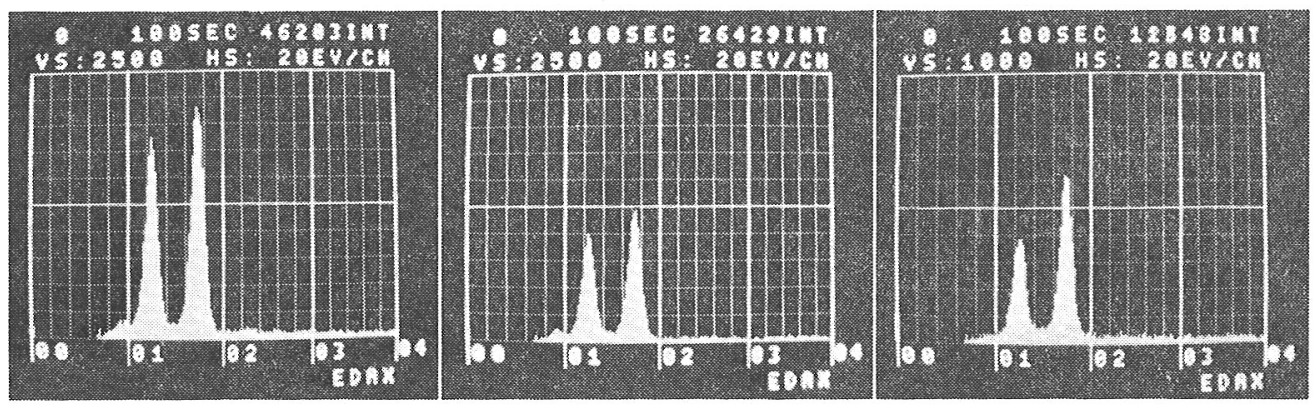

Fig. 6. The X-ray energy spectra for chrysotile fibril in rat lung observed by AEM.

Table 3. $\mathrm{SiO}_{2}$ and $\mathrm{MgO}$ contents of chrysotile in rat lung.

\begin{tabular}{lccc}
\hline & $\mathrm{SiO}_{2}(\%)$ & $\mathrm{MgO}(\%)$ & ${\mathrm{MgO} / \mathrm{SiO}_{2}}$ \\
\hline Original fibrils & 52.6 & 47.4 & 0.90 \\
4 months after injection & 56.7 & 43.3 & 0.76 \\
28 months after injection & 60.2 & 39.8 & 0.66 \\
\hline
\end{tabular}

change in chemical composition of chrysotile fibrils during their residence in rat lungs. The specimens used were obtained from the lungs of rats, which received single insufflation of $10 \mathrm{mg}$ of chrysotile in $1 \mathrm{~m} l$ of saline suspension intratarcheally. Lungs from the rats sacriflced at 4 months and 28 months after injection were subjected to examination. Routine paraffin sections from those lungs were treated with the carbon extraction technique and were analyzed by AEM. ${ }^{22}$ The X-ray energy spectra from the rat lung tissues are shown in Fig. 6.

Table 3 shows the $\mathrm{SiO}_{2}$ and $\mathrm{MgO}$ contents of chrysotile fibrils in the rat lungs together with the ratio of $\mathrm{MgO}$ to $\mathrm{SiO}_{2}$ in these chrysotile fibrils. As can be seen in Table 3, the ratio on $\mathrm{MgO}$ to $\mathrm{SiO}_{2}$ in the chrysotile in rat lungs has a tendency to become small with prolonged retention of fibrils in the lungs. This fact shows $\mathrm{Mg}$ ions are disolved more rapidly than $\mathrm{Si}$ ions from chrysotile fibrils. However, only from this data, it is yet uncertain whether or not Si ions were actually disolved from chrysotile fibrils.

Chemical instability of chrysotile in a living organism has been demonstrated by several researchers. Using daughter decay products of radioactive chrysotile, Morgan and Holmes ${ }^{17)}$ demonstrated that magnesium was rapidly leached from the chrysotile fibers during its biological residence. Langer et al..$^{13) 15) 18)}$ have reported several contributions concerning with asbestos and uncoated fibers in the lungs of asbestos bodies, uncoated fibers in the lungs of asbestos workers and urban dwellers, by electron microscopy technique;

i) The core of asbestos bodies from a chrysotile worker's lung was recognized as chrysotile, of which frequently magnesium was leached out.

ii) Magnesium loss coupled with iron addition could be observed in chrysotile cores of 


\section{N. KOHYAMA et al.}

asbestos obtained from individuals whose exposure history was unknown.

iii) Large chrysotile fibers in asbestos bodies tend to retain chemical identity with chrysotile, whereas chemical degradation appears to effect fine chrysotile fibers.

iv) Amosite remains intact in lung for at least 10 years and large chrysotile fibers may also stay intact for long periods.

v) Uncoated asbestos fibers from the lungs of asbestos workers revealed decreased magnesium content for anthophyllite and amosite, while a slight iron increase was also noted in the same fibers, probably related to an incipient asbestos body formation.

On the other hand, the reactivity of asbestos minerals towards acids and alkalines in vitro is well known. Strong acids rapily decompose chrysotile with removal of all the $\mathrm{MgO}$ and $\mathrm{H}_{2} \mathrm{O}$ components, amounting to about $58 \%$ by weight. Reacting with strong acids, the whole $(\mathrm{Mg} \mathrm{OH})$ sheets in chrysotile is stripped off and chrysotile becomes the silica skelton. ${ }^{19)}$ Although the reaction of chrysotile with dilute acids differs slightly from the reaction with strong acids, the soulubility of $58 \%$ of the chrysotile in such circumstances corresponds to removal of all cations and all hydroxyls in leaving an unhydrated silica skelton. ${ }^{20)}$ Dilute $(0.1 \mathrm{~N})$ hydrochloric acids with chrysotile to give orthosilicic acid and magnesium ions in solution. Also the fiber itself is decomposed by continuous extraction of the chrysotile in hot water. The extracts contain orthosilicic acid and magnesium. The complete breakdown of the chrysotile structure appears to follow a course in which magnesium ions are leached out, leaving fragments of the $\mathrm{Si}-0$ bonding. These fragments are probably of a colloidal form. ${ }^{21}$ According to Pooley, ${ }^{22)}$ characteristic chrysotile diffraction pattern can be obtained from the fiber with up to $50 \%$ removal of the magnesium. Thus, the breakdown of silica tetrahedral sheet takes place only after most or all of the cations are removed from the structure. It can be assumed that remarkable changes in cation concentration in chrysotile could be resulted without any appreciable changes in the silicon content.

Actually on the same lungs in this report Koshi et al. ${ }^{23)}$ (1974) demonstrated that chemically determined silica content was hardly variable up to 24 months after insufflation. This suggests that silicon content of chrysotile fibrils may be regarded as constant in those rat lungs. Considering those facts, it will be concluded that silicon is remained unchangeably in chrysotile fibrils, but magnesium is reduced more easily during long lasting retention of chrysotile fibril in the rat lung. The recalculated values of $\mathrm{MgO}$, assuming $\mathrm{SiO}_{2}$ content is unchanged through the retention periods, are shown in Table 3 and Fig. 7. It can be seen that more than a quarter of the whole $\mathrm{MgO}$ contents leached out from chrysotile fibrils by their residence of 28 months in the rat lung.

Although there are several works concerning with chemical degradation of chrysotile in the lung, comparatively little is known of the length of biological residence in human case, and nothing is known of degradation rate of chrysotile in the lung. It should be added that the rate of decomposition is a direct function of the surface area of the chrysotile fibrils. Verwald et al. ${ }^{24)}$ (1951) observed after injection of chrysotile into 
CHRYSOTILE FIBRILS IN LUNG

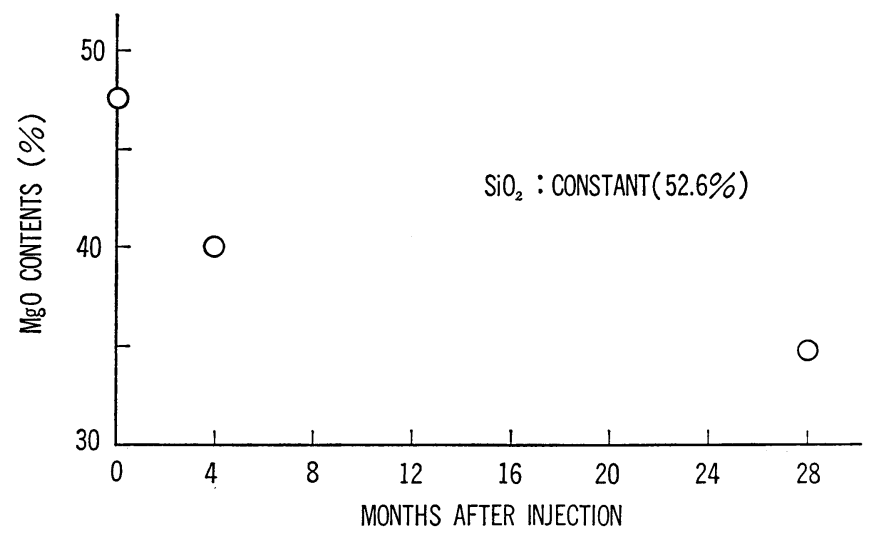

Fig. 7. The $\mathrm{MgO}$ contents for chrysotile fibril in rat lung assuming the $\mathrm{SiO}_{2}$ to be unchanged through the retention periods. These are observed by AEM.

guinea-pig lung that length of the chrysotile was reduced from 20 to less than $3 \mu \mathrm{m}$. It can be considered that chrysotile fibrils are splitting rapidly into their unit fibrils, and their surface areas are greatly increased after inhalation. Because of the difficulty for estimation of their surface area in the lung, it is difficult to estimate accurate degradation rate of chrysotile fibrils in biological environment in this experiment. However, the result of this study suggests that the length of biological residence may be estimated by the measurement of the ratio of $\mathrm{MgO}$ to $\mathrm{SiO}_{2}$ of chrysotlie fibrils in the lung tissue specimens.

The investigation also clearly indicates the vast possibility of the analytical electron microscope (AEM) in determining chemical compositions of the fine particles, qualitatively and quantitatively, in relation to biological effect of chrysotile fibrils in rat lung.

\section{Acknowledgement}

We wish to thank Dr. H. Sakabe, Director of National Institute of Industrial Health, for his encouragement through this work and Dr. H. Yotsumoto of JEOL, Ltd., for his helpful discussions concerning the analytical method. Thanks are also due to Mr. M. Hino of JEOL, Ltd., for his X-ray fluorescence analysis.

\section{Appendix}

The principle proposed by Namae ${ }^{17)}$ (1975) is as follows: The characteristic X-ray intensity $(I)$ produced from the thin specimen is proportional to the product of the current density of the probe $(\rho)$ and the mass of the element in interacted area with the probe $(W)$, which is shown as $I=K \rho W$. When the specimen is thin enough to neglect the matrix effect on characteristic $\mathrm{X}$-rays $(\mathrm{ZAF})$, this $K$ is independent on the composition of the specimen. The details are given in the paper (Namae, 1975). 


\section{N. KOHYAMA et al.}

A standard thin specimen, the thickness is already known, produces the characteristic $\mathrm{X}$-ray intensity of a certain element as follows:

$$
I_{s t}=K \rho W_{s t}
$$

where the mass of the element $\left(W_{s t}\right)$ is already known and the $I_{s t}$ is measured as a standard intensity for the element in the standard.

On the other hand, the same relation is also valied for the unknown specimen, the thickness is not known;

$$
I_{u n k}=K \rho W_{u n k}
$$

From (1) and (2),

$$
W_{u n k}=\left(W_{s t} / I_{s t}\right) I_{u n k}
$$

where the suffixes st and unk on $W$ and $I$ mean the standard and unknown specimens, respectively. $\rho$ is shown as follows;

$$
\rho=\text { Probe intensity/Scanning area on the specimen }=A /\left(l_{x} \cdot l_{y} / M^{2}\right) .
$$

$A$ is the probe intensity on the specimen measured by Faraday cage. $l_{x}$ and $l_{y}$ are the lengths of selected area reduced on cathod ray tube (CRT), and $M$ is magnification on CRT. $\quad I_{s t}$ and $I_{u n k}$ must be measured under the same accelerating voltage and current density of the electron probe. From this equation (3), if $I_{u n k}$ for a certain element in unknown specimen was obtained by analysis, the mass of the element, $W_{u n k}$, would be obtained by the caliculation. In the area of the equation (1) being valid, if the object elements were distributed homogeneously over the area, or even if in homogeneously distributed, in either case the characteristic X-ray intensity would not be changed unless the weight of the object element is varied. That is, the absolute weight of the object elements can be determined without the influence of the thickness of the specimen or size of the small particle in the specimen.

\section{REFERENCES}

1) Henderson, W.J., Chandler, J.A., Blundell, G., Griffiths, C. and Davies, J. (1973). J. Microsc. 99, 183.

2) Kyono, H., Homma, K., Nagatani, T., Watanabe, T. and Kawai, K. (1974). Ihd. Health, 12, 49.

3) Nicholson, W.J. (1974). Environ. Health Perspect. 9, 165.

4) Funahashi, A., Pintar, K. and Siegesmund, K.A. (1975). Arch. Environ. Health, 30, 285.

5) Funahashi, A., Siegesmund, K.A., Drager, R.F. and Pinter, K. (1977). Brit. J. Ind. Med., 34, 95.

6) Henderson, W.J., Evans, D.M.D., Davies, J.D. and Griffiths, C. (1975). Environ. Res. 9, 240.

7) Hayashi, H., Aita, S. and Suzuki, M. (1977). Proceedings of an International Symposium on Industrial Toxicology, Lucknow, India, 1975. in Press.

8) Wager, J.C., Sleggs, C.A. and Marchand, P. (1960). Brit. J. Ind. Med., 17, 260. 


\section{CHRYSOTILE EIBRILS IN LUNG}

9) Selikoff, I.J., Churg, J. and Hammond, E.C. (1964). J. Am. Med. Assoc., 188, 22.

10) Selikoff, I.J., Hammond, E.C. and Churg, J. (1972). Arch. Environ. Health, 25, 183.

11) Rubin, I.B. and Maggiore, C.J. (1974). Environ. Health Perspect., 9, 81.

12) Heppleston, A.G. (1974). Environ. Health Perspect. 9, 295.

13) Langer, A.M., Selikoff, I.J. and Sastre, A. (1871). Arch. Environ. Health, 22, 348.

14) Pooely, F.D. (1976). Environ. Res. 12, 281.

15) Langer, A.M., Rubin, I. and Selikoff, I.J. (1970). Pneumoconiosis; Proc. Int. Conf. Johannesburg, 1969. (Edited by Shapiro, H.A.) 52. Oxford Univ. Press, Cape Town.

16) Namae, T. (1976). J. Electron Microsc. 24, 1.

17) Morgan, A. and Holmes, A. (1970). Pneumoconiosis; Proc. Int. Conf. Johannesburg, 1969, (Edited by Shapiro, H.A.) 52, Oxford Univ. Press, Cape Town.

18) Langer, A.M., Rubin, I., Selikoff, I.J. and Pooley, F.D. (1972). J. Histochem. Cytochem., 20, 735 .

19) Badollet, M. (1963). Encyclopaedio of Chemical Technology, 2, 734.

20) Pundsack, F.L. and Reimschussel, G. (1956). J. Phys. Chem. Ithaca, 60, 1218.

21) Holt, P.F. and Clark, S.G. (1960). Nature, 185, 237.

22) Pooley, F.D. (1972). Brit. J. Ind. Med., 29, 146.

23) Koshi, K., Kawai, K. and Sakabe, H. (1974). Abstracts of Presentations at 47th Ann. Meet. Jap. Assoc. Ind. Health, p. 373. (in Japnese).

24) Verwald, A.J., Durkan, T.M. and Pratt, P.C. (1951). Arch. Ind. Hyg., 3, 1. 